\title{
TRADE LIBERALISATION AND ECONOMIC GROWTH IN MACEDONIA
}

Viktorija Mano-Bakalinov

\section{Abstract}

The objective of this paper is to explore the effects of trade on Macedonian economic growth. The autoregressive distributed lag (ARDL) model is applied on yearly data over the period of 1993-2014. Empirical investigation reveals that an increase of population and openness demonstrate a positive and significant effect on Macedonian economic growth. Given other diverging findings, this suggests that the relationship between trade reforms and growth through the productivity function may vary across transition economies. Nevertheless, the findings of this paper indicate that policies focusing on market liberalisation and opening the economy to trade have a positive effect on Macedonian economic growth, both in the short run and the long run.

Keywords: $A R D L$, growth, reforms, Macedonia, transition.

JEL codes: $C 32, F 63, N 14,011$

\section{INTRODUCTION}

Questions related to what determines the potential growth rate and what reforms could increase growth should be central to deciding a country's policy agenda. In the context of the Macedonian economy, a relevant question is the extent to which market reforms can be considered as the major drivers of economic growth. Since the Macedonian transition process in the 1990s, structural reforms, as well as macroeconomic adjustment to safeguard economic stability in recent years, should have increased the potential growth rate. Looking ahead, policy makers need to know what reforms could increase Macedonia's growth further and lead to faster income convergence with neighbouring countries and the EU.

Transition economies have been perceived as an interesting area of research by many academics, initially because of the remodelling of the institutions due to the change of regime, and later owing to the business environment that has emerged through the movement toward a market economy (Bevan, Estrin

\section{Viktorija Mano-Bakalinov}

Roehampton University London, UK

E-mail:manov@roehampton.ac.uk

\section{Acknowledgements}

The author would like to thank the many helpful feedback received by Reza Arabsheibani, professor in economics at the University of Roehampton and Katja Jonas for reading and discussing the findings of the paper and their invaluable comments. I also want to thank the scholarships received from the University of Roehampton (London-UK), without the institution's support this article would not be concluded. 
and Meyer 2004). The transition from socialism to capitalism in Central - Eastern (CEE) and South - Eastern Europe (SEE) was perceived by academics as a political, social and economic process (Bevan and Estrin 2000). Despite the highlighted optimism concerning the benefits from economic policies in these countries, the expectations were not realised. The author seeks to contribute to this debate by considering the case of a transition economy in South - East Europe - Macedonia.

As a small open economy, Macedonia is sensitive to fluctuations in international markets and has suffered contraction in GDP growth due to contagion and spillover effects from external factors. The aim here is to further investigate the argument presented in the economic literature that the market liberalisation process and openness of a transition economy lead to an increase in GDP and therefore economic growth. The objective of this paper is to test the traditional view that the IMF's prescription of trade liberalisation policies in a planned economy will bring openness to the market and economic growth. As far as the author is aware, this is the first attempt to empirically estimate the determinants of growth in Macedonia, and which includes more recent macroeconomic data and the use of a more developed method than a simple multiple regression analysis. Only a few inconclusive empirical studies have been carried out to determine which explanatory variables matter for Macedonia's economic growth and these have been done mostly by using panel or cross-national analysis (Botric and Skuflic 2006; Krstevska and Petrovska 2012; Stancheva - Gigov 2014). In line with this, quantitative secondary data is used, coupled with time-series autoregressive distributed lag (ARDL) analysis to determine the effect and the explanatory power of macroeconomic variables on economic growth. The findings of this study indicate that some of the economic reforms have a statistically significant and positive influence on GDP. It is argued that this result is important, not only from the perspective of a transition economy, but also in the general context of the economic reform - growth debate.

The remainder of this paper is organised as follows. Section two presents the model implemented in this study and sketches out the context under study. Section three discusses the theoretical background of this paper. Section four provides insight into the methodology used in this paper, leading to section five, which interprets the findings from this analysis. Finally, section six presents the concluding summary as well as discusses the limitations of this research.

\section{OVERVIEW OF THE MACEDONIAN CONTEXT}

Since the aim of this paper is to investigate the role of trade liberalisation policies in Macedonian economic growth, it is essential to present the context under investigation. In this section the author offers a thumbnail sketch of Macedonia. The author argues that in order to evaluate the policies implemented by international financial institutions (IFI) it is necessary to understand the specificity of the Macedonian context.

Macedonia is a small country located in the centre of the Balkan Peninsula in SEE. It is landlocked by its neighbours Kosovo and Serbia (to the North - East and North - West respectively), Bulgaria (to the East), Greece (to the South) and Albania (to the West). The population of Macedonia is 2.1 million citizens, based on forecasted data from the United Nations in 2012 (since a census has not been conducted since 2002). The capital is Skopje, the main language is Macedonian and the majority religion is Christian Orthodox.

The performance of the Macedonian economy can usefully be assessed in three distinct periods: the first is the period from 1992-2000, roughly the first decade following the country's independence; the second period from 2001-2008 and the third period from 2009 - 2015. This first period comprises the turbulences and difficulties facing a newly independent country. Figure 1 below indicates stagnation and even shrinkage of the economy during the period 1992-1996 and then a small expansion in the period 1996-1999, with a

Figure 1: Economic overview of Macedonia

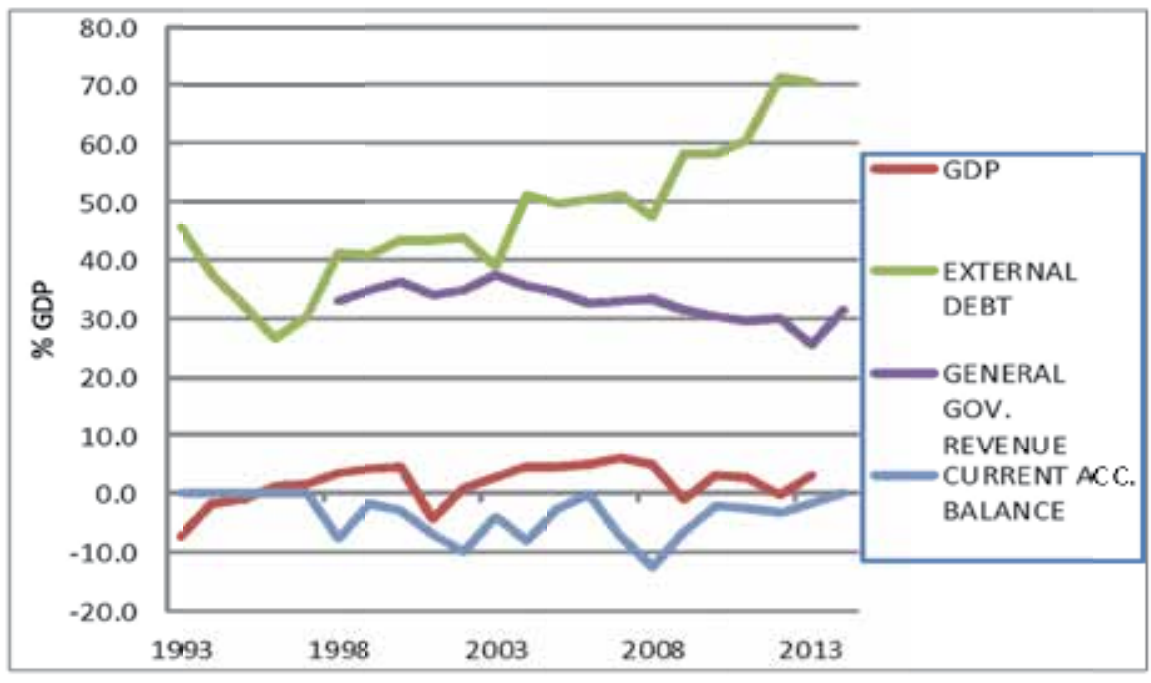

Source: Data from the National Bank of Macedonia, own calculations. 
downturn during the Kosovo crisis in 1999 and a sharp downturn in the Macedonian economy in 2001 as a result of the ethnic conflict in the country. In the period from 1996 to 1999 significant economic growth is noticed due to the smaller increase in the GDP per capita and the low external debt.

In the period between 2001 and 2008 (especially after 2001) the economies of the SEE region (including Macedonia) had enjoyed a mini-boom, with a stable increase in GDP mainly fuelled by large capital inflows of international finance (such as bank credits enabling increased domestic borrowing by both firms and households).

The third period, 2009-2015, demonstrates a stable temporary increase in GDP. However, in 2009 and 2012 there was a downturn in the Macedonian economy due to unfavourable global trading conditions, more specifically as a result of the US and the EU crises. Unlike the 1996-1999 period, where both GDP and GDP per capita were increasing, the period after 2008 (since the occurrence of the US and Greek crisis) the rate of economic growth was lower (smaller increase in GDP per capita) since the standard of living was failing. Investments have also indicated a significant growth throughout this period, with exceptions in the years 2008 and 2012, where a slower increase in capital inflow has been projected due to the ethnic conflict in Macedonia, the US crisis and the Greek crisis.

Since Macedonia's independence, inflation rates have been high due to structural problems and the macroeconomic instability in the country. The years 2001, 2008 and 2012 demonstrate increased inflation due to domestic political instability and international financial crises. This also indicates low competitiveness due to increased prices on imports. Aside from these specific years, inflation rates have been changeable, sometimes even falling to low levels, which indicates that import prices have the potential to decline further. The trade and current account balance in the first decade was relatively high and in the second decade normalised. However, the years around the ethnic conflict (in 2001) and the US crisis (in 2007/8) demonstrate an increased current account balance, a fall that was crystallised in the last few years of the data series as the crises led to a decrease in the consumption of luxury goods. Government debt had been stable from its peak in 2001, and even in the period during the US crisis the debt did not increase, but since the Greek crisis and the withdrawal of Greek capital, government debt has increased again, reaching levels of 38\% in 2014 (Expansion 2014). This increase in government debt can be explained by the implementation of government programs in order to stimulate the private sector during times of crisis, low trade and low capital inflow from Greece. Other programs that increased the government debt included efforts at attracting foreign greenfield investment in newly-created free economic zones, which provided low-tax free land, faster custom services and other financial benefits for foreign investors (DTIDZ 2014). Finally, a major government-funded development project started in 2010 and known as 'Skopje 2014', which consists mainly of the construction of new government buildings, monuments and museums also contributed to the debt. However, even though such programs implemented by the government have increased government debt, unemployment rates have not decreased and the economy has not experienced significant growth.

Considering the background numerical analysis of the data provided, Macedonia's transition should be considered an interesting context to study within the aim of understanding which key variables play a crucial role in economic growth for a transition economy during this period.

\section{THEORETICAL BASIS OF THE INVESTIGATION}

Mainstream economic literature covers many theories that have attempted to understand economic growth. However, the majority of the current literature highlights one main theory that provides an understanding of the sustainability of long-run economic growth; the neo-classical theory.

The 'neo-classical growth theory,' or the SolowSwan model, argues that the economy's long-run growth is dependent on changes (exogenous factors to the capital-labour ratio), such as saving, technological progress, population and capital depreciation (Solow 1956; Swan 1956). In other words, if two countries have the same level of technology, savings, population and capital depreciation, but vary in the level of capital-labour ratio, then the economy with lower capital-labour ration will grow more rapidly than the other economy with a higher capital-labour ratio (Solow 1956). Thus, the neo-classical model predicts that countries over time with different percapita income will converge. This is named 'absolute convergence' (Swan 1956). According to Solow-Swan (1956), economies tend to converge to their steady state, meaning that their long run economic growth will be stable. Therefore, the 'neo-classical growth theory' argues for a short-run growth by accumulating physical capital and long-run growth reached through changes in the exogenous factors mentioned above. However, this growth model is feasible in a closed economy where there is no interaction with the rest of 
the world (Daud et al. 2013).

Over the past decades, academics and policy-makers have shown consistent interest in and have made efforts to investigate and develop a theoretical link between trade liberalisation and economic growth. A potential positive relationship between openness and growth has generated an 'unprecedented wave of unilateral trade reforms', arguing that about 100 economies have undertaken certain trade reforms in the last 20 years (Greenaway, Morgan and Wright 2002: 230). Greenaway et al. (2002) emphasise through their research that there is a positive relationship between the growth of exports and growth of GDP in the long run. Thus, they argue that countries with a higher level of openness grow faster over time. While Edwards (1998) argues that the relationship between trade and openness is robust in the long term, Rodriquez and Rodrik (1999) question this conclusion. They highlight that their research indicates an overstated relationship between outward trade and growth, whereas the link between inwardly orientated trade and growth provides limited evidence (Rodriquez and Rodrik 1999). There has also been extensive research undertaken on the effects of trade reform on growth in the short run. The literature is inconclusive, since some studies bring forward a positive relationship, some indicate no relationship, while some even show a negative relationship. On one hand, Harrison and Hanson (1999) suggest that static trade models demonstrate that shifts toward openness can increase growth in the short run. Rees and Tyers (2004), on the other hand, argue that due to the removal of import barriers, openness can be contractionary in the short term in some economies. Finally, Greenaway et al. (2002), in their analysis demonstrated that the relationship between trade and growth is in the shape of a ' $J$ ' curve, increasing initially but declining at certain levels of trade (Shahbaz 2012). This inconclusiveness is explained by Harrison and Hanson (1999) by the fact that different studies involve different proxies for trade liberalisation and use different robustness tests. The contribution of this paper is to provide a deeper understanding of the relationship between certain trade policies and their effect on economic growth in transition economies, especially since the Macedonian context has not been researched enough.

This paper contributes to the field of development economics specifically in the area of transition economies. Several studies have focused on SEE transitional growth and provided possible explanations why the SEE transition economies did not become the economic powerhouse they were expected to become (Bartlett 2009; Bevan and Estrin 2000; Horvat 2004). Academics in this area of research have attributed the low growth rate of SEE transition economies to a number of issues. Some academics have mentioned weak institutions as an important factor that has influenced transitional growth (Efendic and Pugh 2015; Manolova, Eunni and Gyoshev 2008). Despite these economies being open and growing, academics have pointed out that investment is relatively low compared to the rest of the CEE transition economies (Bevan and Estrin 2004). Fiscal pressures are another issue, which due to weak revenue performance, weighty debt service and high input costs put a strain on government spending, while the political turbulences in the region serve as a disincentive for investors to invest in the private sector (Bocchi 2008). Macedonia's high dependency on the external environment and its long-standing constraints to growth - lack of adequate infrastructure, low investment, high unemployment and government weakness -still constrain growth.

By focusing on the trade reforms introduced during Macedonia's transition, the author sheds light on the diverse effect that specific macroeconomic determinants have on GDP both in the long and short runs. It is here that the author aims to provide an understanding of the openness of the Macedonian economy and to what extent certain country specific variables can explain economic growth in Macedonia.

\section{METHODOLOGY}

The existing methodology of the empirical investigation follows the voluminous growth regression literature initiated by Barro and Sala - I - Martin (1995). Depending on the aim of the study and insights, various explanatory variables have been found to be significant in literature on the relationship between trade liberalisation and growth.

\subsection{The Data, Sources and Data Definition}

This study takes advantage of secondary data on macroeconomic variables, extensively used in the literature regarding similar transition economies. The data set is obtained from the State Statistical Office of the Republic of Macedonia, ${ }^{1}$ the National Bank of Macedonia ${ }^{2}$ and International Monetary Fund reports.

\footnotetext{
1 Population and Secondary Schooling are annual observations sourced from SSORM. The Openness variable is constructed by the sum of total exports and imports to the GDP and is an index.

2 Inflation, the FDI and the GDP are from both NBM and IMF reports and are also quarterly. Due to the non-availability of quarterly data for the rest of the variables, the series were interpolated to derive annual data from the available quarterly data.
} 
The sample period runs from 1993 to 2014, making for a total of 21 observations. All data are transformed to their growth rates, and their frequency is annual. For the analysis of the data collected, the author used a STATA software package, which is a program used in research work in the fields of economics, sociology, and the political and medical sciences.

\subsection{Model Specification and Explanation of the Variables}

In order to use appropriate model specification, it is crucial to formulate a general model that encompasses the main determinants of growth identified by the theory. This section relies on empirical specification used by Daud, Ahmad and Azman-Saini (2013), which uses time-series regression analysis of macroeconomic determinants of growth for the Malaysian economy. The author applies this specification with adaptations for the case of the Macedonian economy.

This specification has been chosen as the most appropriate according to two criteria, the analysis of a transition economy and the application of a timeseries linear regression analysis. Considering both the Macedonian and Malaysian context there are similarities that need to be highlighted. First of all, the transition process of the Malaysian economy resembles the transition of the Macedonian economy in many ways. Both economies followed suggested liberalisation policies by the IMF, which at their core were very much alike and based on the standard neo-liberal prescriptions - rapid shock therapy, trade and financial liberalisation and privatisation (Gore 2000). Second, considering the theory discussed in the previous section and the fact that little research has been conducted on the growth of transition economies using time-series analysis, this specification and estimators were found helpful for the objectives of this paper, especially as most of the studies exploring the debate around trade and growth in small transition economies in Europe use panel or cross country analysis to determine the significant macroeconomic indicators to growth (Backe and Gardo 2012; Bartlett and Prica 2012; Bartlett 2009).

Considering the explanation of the variables in the previous section, before moving to the model itself the author would like to justify the choice of variables. The model adopted and adjusted in this paper is based on the neoclassical growth model argued in section three. According to the theoretical underpinnings of this paper, an economy's growth in the longterm is based on exogenous factors such as population, savings, technological progress and capital depreciation (Solow 1956). The aim of this paper is to investigate the long-term determinants that change the growth of the economy. Thus, by considering certain variables such as FDI, POP, OPEN and INF (please see their explanation below), I take in consideration the exogenous factors that potentially affect the growth of the Macedonian economy. However, on the other hand, since the neo-classical theory argues for the existence of the 'absolute convergence', the model includes the variables POP and SEC (please see their explanation below), in an attempt to understand the short-run relationship between accumulated physical capital and growth. Thus, I have chosen this model as the most appropriate because it considers both the relationship of the accumulated physical capital and short-run growth as well as exogenous factors and long-term growth (Swan 1956).

Having said this, the model that is adopted and adjusted in this paper uses Villanueva's (2003) neoclassical growth model as a point of reference. Through this model, it is argued that a country that intends to increase its economic growth will increase its savings, leading to more investments and increased economic growth. Daud et al. (2013) have used this model to explain economic growth by considering traditional macroeconomic variables and their effect on GDP:

\section{$\mathrm{GDPt}=\mathrm{a}+\mathrm{b} 1 \mathrm{FDIt}+\mathrm{b} 2 \mathrm{POPt}+\mathrm{b} 3 \mathrm{GOVt}+$ \\ b4 OPENt + b5 EDt + b6 DSERVt+ et}

This specification is applied to the Macedonian case by excluding one of the variables (debt service payment) since it is not available. Also, the variables GOV and ED are excluded since they are highly correlated with other variables, and INF and SEC are added as significant variables according to the theoretical underpinnings discussed above. Thus the adjusted equation for Macedonian case is the following:

$$
\begin{gathered}
\mathrm{GDPt}=\mathrm{a}+\mathrm{b} 1 \mathrm{FDIt}+\mathrm{b} 2 \text { POPt }+\mathrm{b} 3 \mathrm{INFt}+ \\
\mathrm{b} 4 \text { OPENt }+\mathrm{b} 5 \mathrm{SECt}+\mathrm{e} \mathrm{t}
\end{gathered}
$$

GDPt: Gross domestic product at time t

FDIt: Foreign direct investments at time $t$

GOVt: Government revenue at time $t$

OPENt:Trade openness at time $t$

POPt: Population at time $t$

EDt: External Debt at time $\mathrm{t}$

DSERVt: Debt service payment at time $t$

SECt: Percentage of population enrolled in secondary school at time $t$

INFt: Inflation index at time $t$

et : error term at time $t$ 
The variables POP, SEC and FDI represent the changes in the rate of human capital and capital factor input in the production function (as presented by the endogenous growth theory). Since fiscal austerity, monetary policy, market liberalisation and privatisation were the main milestones of the 'Washington Consensus' in the decades of the 1980s and 1990s (Stiglitz 2002, p.54), the rest of the variables OPEN ${ }^{3}$ and INF account for country-specific government policies implemented relating to fiscal and monetary policies. This increased openness of a market provides more possibilities to finance an increased external debt, raises the level of foreign reserves, increases return on investment and productivity, as well as increases the government revenue (Kose, Prasad and Terrones 2003). As argued previously, traditional economists perceive tight fiscal policy as a stimulator of strong budget constraints that encourage restructuring, which also stabilises the level of inflation indicating the determination of the government to carry out reforms.

\subsection{The Auto Regressive Distributed Lag (ARDL) Model}

Since OLS is appropriate if all variables are stationary $(I(0))$, and the Johanson approach if all variables are stationary $(I(1))$, researchers could not obtain reliable results by using these methods if one of the variables was non-stationary (Johansen and Jesulius 1990). The ARDL model was introduced by Pesaran, Shin and Smith (2001) in order to incorporate a mixture of $I(0)$ and I(1) data, and involves a single equation set-up different variables are assigned different lag-lengths when they enter the model. The reason for the choice of the ARDL model is that it is robust for small sample sizes (Mah 2000; Tang and Nair 2002). Therefore, the ARDL bound test employed here is used to model the data appropriately and extract both long and shortrun relationships.

This approach has several desirable statistical features. First, the co-integrating relationship can be estimated easily using OLS after selecting the lags order of the model. Second, it allows testing simultaneously for the long and short--run relationships between the variables in a time series model. Third, in contrast to the Engle-Granger and Johansen methods, this test procedure is valid irrespective of whether the variables are I(0) or I(1) or mutually co-integrated, which means that no unit root test is required. Fourth, in spite of the possible presence of endogeneity, the

3 Presented as an index constructed from IMP, EXP and GDP
ARDL model provides unbiased coefficients of explanatory variables along with valid t-statistics. In addition, the ARDL model corrects the omitted lagged variable bias (Inder 1993). Finally, this test is very efficient and consistent in small and finite sample sizes.

The first stage of the analysis is to define the lag order and see what lag is appropriate for each variable in the model. This is done by using a VARSOC table (Vector Auto Regressive Specification Order Criterion). The order of the lags in the ARDL model is selected using appropriate selection criteria, such as Akaike Information Criterion (AIC), final prediction error (FPE), Schwarz's Bayesian information criterion (SBIC), the Hannan and Quinn information criterion (HQIC), log likelihood (LL) and the likelihood ratio test (LR(p)). When more than one criterion brings forward a specification that satisfies the diagnostic testing, the model with the shortest lags is chosen. The testing is done by using the maximum lag length (4) for each variable, since it has been argued that selection by using shorter lags can lead to correlation issues, misspecified models and losing degrees of freedom (Pesaran et al. 2001).

After this step, the stationarity of each variable at level and at first difference needs to be checked by using an $A D F$ test and focusing on the $Z(t)$ statistic. Once the variables have been checked and shown that they are not I(2), the analysis proceeds to the next stage, which is the analysis of the ARDL model.

The null hypothesis that is investigated here argues for a relationship that is not co-integrating between the examined variables irrespective of whether the variables are stationary at different levels $\mathrm{I}(1)$ or $\mathrm{I}(0)\left(\mathrm{H}_{0}: \theta_{1}=\theta_{2}=\theta_{3}=\theta_{4}=\theta_{5}=0\right)$. The alternative hypothesis is that $\mathrm{H}_{0}$ is not true. If the value of the statistic from a Wald test is outside the range of the critical bounds (both lower and upper) then a conclusive inference can be made without considering the order of integration of the variables ( $\mathrm{F}$ - statistics $>$ upper critical bound $=>\mathrm{HO}$ is rejected; $\mathrm{F}<$ lower critical bound $=>\mathrm{H} 0$ cannot be rejected). Otherwise, if the F-statistic falls between the upper and the lower critical bound then a conclusive inference cannot be made.

Assuming that the bounds test leads to the conclusion of co-integration then a meaningful estimate of long-run equilibrium relationship between variables is possible, as well as estimating the usual ECM for the short-run coefficients. However, co-integration does not suggest that the coefficients are stable; if they are not stable the results will lose their reliability. In order to avoid this, Pesaran and Pesaran (1997) recommend testing for long-run parameter stability by using the cumulative sum of recursive residuals (of square) (CUSUM) and (CUSUMQ) test. These two tests can be 
used without the information of the structural break points and test for the null hypothesis, which is that all coefficients are stable (Brown et al. 1975). The CUSUM detects systematic changes in the regression coefficients and the CUSUMQ uses the same procedure but focuses on situations when the departure from the constant of the regression coefficient is unexpected and sudden. Normally, the graph plot should stay inbetween the 5 percent significance level, which indicates the absence of any instability of the coefficients, suggesting that the parameters of the model do not experience any structural instability during the study period.

\section{RESULTS AND FINDINGS}

\subsection{Varsoc}

First, the author checks the optimum lag order. This is done using a VARSOC Table (Vector Auto Regressive Specification Order Criterion), which is available in STATA. The VARSOC function uses seven criteria that determine the optimum lag to be used. Thus the optimum lags of ARDL $(p, q 1, q 2, q 4, q 5)$ for the variables GDP,OPEN,POP,INF,FDI and SEC is ARDL $(1,3,1,0,0,3)$.

\subsection{Augmented Dickey Fuller}

Even though testing the variables is not essential according to the ARDL model, it is necessary to undertake a unit root test in order to detect the right model that should be used. The standard Augmented Dickey-Fuller (ADF) unit root test was exercised to check the order of integration of all variables. The results obtained are reported in Table 1 . Based on the ADF test statistic, the variables rejected the null hypothesis. The values in Table 1 reject the null hypothesis of the unit root according to McKinnon's (1974) critical values. The null hypothesis is rejected at a $1 \%$ significance level according to the critical values in the table below.

The GDP variable is stationary according to the ADF test when the model does not incorporate the trend with no lags. The absolute value of the t-statistic (4.071) is much higher than the absolute critical values according to the ADF tables considering only intercept (1\%: -2.539, 5\%: -1.729, 10\%: -1.328). The FDI variable is stationary according to the ADF test when the model considers first difference with trend and the constant of the variable with no lags. The absolute value of the t-statistic (5.653) is much higher than the absolute critical values according to the ADF tables (1\%: 4.38, 5\%: 3.6, 10\%: 3.24). The POP variable is stationary according to the ADF test when the model considers first difference with trend and the constant of the variable with one lag. The absolute value of the t-statistic (4.031) is much higher than the absolute critical values according to the ADF tables (1\%: 4.38, 5\%: 3.6, $10 \%$ : 3.24). The OPEN variable is stationary according to the ADF test when the model considers first difference with trend and the constant of the variable with one lag. The absolute value of the t-statistic (4.853) is much higher than the absolute critical values according to the ADF tables (1\%: 4.38, 5\%: 3.6, 10\%: 3.24). Finally, the variable SEC appears to be non-stationary according to the ADF test (no trend or constant) at first difference and at 0 lags, and the INF is stationary at level and 0 lags.

Therefore, the table below demonstrates that half of the variables reject the hypothesis of unit root at level (GDP, INF and POP) and the rest of the variables reject the null hypothesis of the ADF test at first difference (OPEN, FDI and SEC). Noticeably, the mixture of both I $(0)$ and I(1) variables would not be possible to analyse under the Johansen procedure. This gives a good justification for using the bounds test approach, or the ARDL model, which was proposed by Pesaran et al. (2001).

Table 1: ADF Test

\begin{tabular}{|l|r|r|r|r|r|}
\hline \multirow{2}{*}{ ADF TESTS } & \multicolumn{3}{|c|}{ AT LEVEL } & \multicolumn{2}{c|}{ AT FIRST DIFFERENCE } \\
\hline & $\begin{array}{c}\text { Constant and } \\
\text { trend }\end{array}$ & Constant & $\begin{array}{c}\text { No trend or } \\
\text { constant }\end{array}$ & $\begin{array}{c}\text { Constant and } \\
\text { trend }\end{array}$ & $\begin{array}{c}\text { Constant } \\
\text { No trend or } \\
\text { constant }\end{array}$ \\
\hline GDP (0) & -2.475 & 1.122 & $(4.071)^{*}$ & & \\
\hline OPEN (3) & -1.976 & -0.135 & 1.186 & $(-4.853)^{*}(0)$ & \\
\hline INF (0) & $(-32.048)^{*}$ & $(-36.877)^{*}$ & $(-39.586)^{*}$ & & \\
\hline POP (1) & -4.200 & $(-4.031)^{*}$ & 1.808 & & \\
\hline FDI (0) & -3.240 & -3.209 & -1.575 & $(-5.653)^{*}$ & \\
\hline SEC (3) & -3.653 & -2.909 & 0.253 & & \\
\hline
\end{tabular}




\subsection{Co-integration test and Correlation matrix}

Past studies have used different techniques of co-integration; but all of them pose certain limitations. The first limitation is that these techniques may not be appropriate when the sample size is too small (Pesaran et al. 2001). For this study the author uses the bounds testing co-integration approach developed by Pesaran et al. (2001), which is more robust for the small sample. The calculated F-statistics for the co-integration test is shown in the appendix. The value of the F-statistics for the model above (71.10) is higher than the upper bound critical value $(3.516-4.781)$ at the $1 \%$ level of significance, using constant and no trend. This implies that the null hypothesis of no co-integration is rejected. Therefore, there is a co-integrating relationship among the variables.

Considering the correlation of the variables mentioned in the previous sections, the author has analysed the level of correlating relationship between the variables in the first model (presented by equation 1 in section 4.2). Thus, certain variables such as ED and GOV that showed high correlation with the rest of the variables in the model were exempt and another model was constructed that included the variables presented by equation 2 in Section 4.2. It is argued that attempts at applying the regression technique to highly multi-collinear independent variables results in sensitive parameter estimates to changes in the model or the sample coverage (Farrar and Glauber 1967). However, Liu (1960) argues that data limitations rather than theoretical limitations are primarily responsible for a persistent tendency to oversimplify econometric models. Considering the fact that the Macedonian context provides limited data points (due to the recent independence of the country) and not a huge variety of measured variables (due to poor institutional development), the author has attempted to lower the multicollinearity effects by disregarding some of the variables in order to ensure a more reliable result.

\subsection{ARDL and Diagnostic Tests}

The goodness of fit of the specification, that is, $R$ squared and adjusted R-squared, is 0.79 and 0.50 , respectively. The estimated coefficient of the long-run relationship between GDP, OPEN, FDI, INF, SEC and POP are expected to be significant:

$\log \mathrm{GDP}_{\mathrm{t}}=3.639+0.008 \mathrm{OPEN}_{\mathrm{t}}+0.015 \mathrm{FDI}_{\mathrm{t}}+$ $0.004 \mathrm{POP}_{\mathrm{t}}-0.0091 \mathrm{NF}_{\mathrm{t}}-0.007 \mathrm{SEC} \mathrm{C}_{\mathrm{t}}$

Equation (3) presents the correlation of the variables with GDP in the long run. From the table below it is clear that in the long run, the trade openness variable significantly affects the level of GDP (significance level $5 \%$ ). In other words, as the more open an econo$m y$ is to trade, the higher the GDP. Inflation has a negative effect on GDP in the long run but according to the table above, this variable is not statistically significant. The FDI variable indicates a positive relationship with the GDP, meaning that as FDI increases GDP will also increase. However, the ARDL model below does not indicate a significant effect of FDI on GDP. The POP variable has a positive significant effect on GDP, according to the $t$ values in the table above (significance at level 1\%). Lastly, the variable measuring the percentage of young population enrolled in secondary school has a positive but insignificant effect on GDP in the long run.

The robustness of the model has been defined by several diagnostic tests such as the Breusch-Godfrey serial correlation LM test, the Jacque-Bera normality test and the Ramsey RESET specification test. All the tests disclosed that the model has the aspirational

Table 2: Growth and macroeconomic determinants Dependent Variable: Logged value of annual GDP in domestic currency

\begin{tabular}{|l|c|c|}
\hline Variable & Coefficient & $\mathrm{P}>|\mathrm{t}|$ \\
\hline InGDP1 & -0.681 & 0.044 \\
\hline Long Run & & \\
\hline OPENL1 & & \\
\hline INFL1 & $0.00782^{* * *}$ & 0.037 \\
\hline POPL1 & -0.0098 & 0.804 \\
\hline InFDIL1 & $0.00376^{* *}$ & 0.012 \\
\hline SECL1 & 0.01472 & 0.328 \\
\hline & -0.0073 & 0.399 \\
\hline Short Run & & \\
\hline Constant & & \\
\hline OPEND1 & 3.639 & 0.102 \\
\hline INFD1 & $0.0054^{* * *}$ & 0.038 \\
\hline POPD1 & -0.00063 & 0.819 \\
\hline InFDID11 & 0.00641 & 0.173 \\
\hline SECD1 & 0.00382 & 0.623 \\
\hline & 0.0135 & 0.127 \\
\hline Number of Observations & 20 & \\
\hline R2 & 0.791 & \\
\hline R2 (Adjusted) & 0.502 & \\
\hline & & \\
\hline Model Diagnostics & & \\
\hline SK test (test for normality) & 6.95 & 0.0310 \\
\hline Breusch Godfrey LM & 2.235 & 0.1349 \\
\hline Breusch-Pagan \\
Heteroskedasticity test & 4.24 & 0.5149 \\
\hline Ramsey RESET & & \\
\hline & 2.52 & 0.1071 \\
\hline & & \\
\hline & & \\
\hline & & \\
\hline
\end{tabular}


econometric properties, a correct functional form and the model's residuals are serially uncorrelated, normally distributed and homoscedastic. Hence, the results reported are valid for reliable interpretation. The key regression statistics and the diagnostic test statistics are given below. The relatively low value of the adjusted R - square (0.50) for the ARDL models indicates the low level of the overall goodness of the models, which makes it not as satisfactory as models with other higher $\mathrm{R}$ square values. This can be explained by the limited data points included and the few variables used in the model.

The diagnostic test results show that the model passed the test for normality and serial dependence (tested with the Breusch-Godfrey LM test). The model also passed the Ramsey RESET test for misspecification by not rejecting the null hypothesis. This test indicates that this model does not suffer from misspecification and no non-linear values can help to explain the response variable. However, the results indicate that heteroscedasticity exists in both of the models. Since the time series constituting both the equations are of mixed order of integration, i.e., I (0) and I (1), it is natural to detect heteroscedasticity.

The cumulative sum of squares of recursive residuals (CUSUM) plots show the blue line within the boundaries on both graphs in the appendix. The CUSUM and CUSUMSQ plotted against the critical bound of the 5 per cent significance level show that the model is stable over time. Thus these graphs indicate the absence of any instability of the coefficients, suggesting that the parameters of the model do not experience any structural instability during the period examined.

\subsection{Interpretation and Findings}

Several studies have focused on SEE transition growth and provided possible explanations why the SEE transition economies did not become the economic powerhouse they were expected to become (Bartlett 2009; Bevan and Estrin 2000; Horvat 2004). Academics in this area of research have attributed the low growth rate of SEE transition economies to its weak institutions (De Melo et al. 2001; Campos and Kinoshita 2008). The main aim of this study is to investigate to what extent other factors than weak institutions and the initial conditions in transition economies have had a significant effect on economic growth. Considering the neo-classical growth theory argued in Section 3, the economy's long-run growth is dependent on changes (exogenous factors on the capital-labour ratio), such as saving, technological progress, population and capital depreciation (Solow 1956; Swan 1956). Thus, the objective in this paper is to understand which factors make changes that affect the long-term growth in a transition economy. The analysis in the previous section highlights the factors that affect long-term and short-term economic growth.

Since neo-classical economic theory predicts that countries with different per-capita income converge over time, the author's second objective is to explore this convergence amongst transition economies (Swan 1956). Reviewing the literature, it can be argued that this 'absolute convergence' does not take place amongst transition economies. As argued in Section 3 , economies tend to converge to their steady state, meaning that their long-run economic growth will be stable, but this is not the case in the Macedonian context.

This furthermore relates to the argument in Section 3 that the 'neo-classical growth theory' argues for short-run growth by accumulating physical capital and long-run growth reached through changes in the exogenous factors mentioned before. Therefore, the paper's third objective is to explore short-run and long-run growth, what factors influence them and to what extent they are different. In light of these theoretical assumptions supported by the neo-classical economic growth theory, the results presented in the previous table are discussed here. By highlighting the factors that influence short-term growth and those that influence long-term growth, and by providing discussion around the theoretical background of this paper, the author brings forward the results of this analysis and moves the discussion toward linking these findings to possible policy recommendations.

As argued previously, the benefits of using an ARDL model include the ability to investigate the effects of macroeconomic determinants in the long and short runs. The short-run ARDL analysis indicates the significance of one variable - the openness of the economy towards foreign markets. The other macroeconomic determinants do not indicate any statistical significant relationship with GDP. This demonstrates the importance of liberalisation policies in the Macedonian economy and the opening up of the market to exports and imports with other countries in the short term.

Based on the ARDL analysis in the long run it can be concluded that only two variables out of the five variables included in the model are statistically significant in the long run. The rest of the variables might have an influence on GDP change in the long run, but are not shown to be significant based on the specific model used in this study. This supports Sachs's (1996) argument that the sum of policies (referred to as an aggregate index) are those which bring significant results, whereas when these reforms are regarded 
separately, they show mixed results related to the significance of the coefficients (Aziz and Wescott 1997). Therefore, the more structural and liberalisation reforms are implemented in a country, the higher the increase of its growth performance (Berg and Pattillo 1999). However, in order to understand the effect of each variable on GDP from the analysis above, the author approaches these variables separately but at the same time attempting to present an 'aggregated' interpretation of the results.

According to the long-run results presented above, the openness of Macedonia (presented by the OPEN variable) has a positive significant impact on GDP in the long run. This long-run result is consistent with the theoretical discussion, since one of the main pillars of the economic reform program suggested by the IMF is based on trade liberalisation and market openness. This positive significant relationship with GDP demonstrates that as the country increases its trade openness with other economic partners, the GDP grows as well. In addition, population has a positive and significant impact on overall GDP growth in the long run. Thus, the increase of the population in Macedonia positively affects GDP primarily through the increase of human capital and labour. Based on the insight of this analysis, policies focusing on liberalising the market and opening the economy to trade with other countries have a positive effect on Macedonian economic growth, and with the increase of the population the labour rate of Macedonia increases, which positively affects the productivity function through human capital.

\subsection{Limitations of the Study}

From a technical stand point, it is important to distinguish a number of limitations. The study is based on a data set that is constructed from the publications of the NBM, IMF and SSORM. The reliability and accuracy of that data will therefore affect the robustness of the results of the present study. All efforts have been made to ensure the accuracy of the data, but this potential data problem remains. Considering the fact that this study investigates a context that provides a limited number of annual data points, the author has adjusted the study. In other words, according to Leybourne et al. (2005), the Augmented Dickey - Fuller (ADF) test has good size and power properties when it is compared with other tests. Considering the fact that the data consists of only 21 points, the author has taken advantage of the ADF test since it requires a much shorter sample size than the conventional unit root test to attain the same statistical power. Moreover, the ARDL procedure provides other benefits that have assisted in overcoming the limitations of this study related to its small sample size. The ARDL procedure does not require all the variables in the system to be of an equal order of integration (as do other techniques, such as Johansen co-integration). Thus, this means that the ARDL can be applied irrespective of whether underlying regressors are purely I(0), I(1) or mutually co-integrated (Ozturk and Acaravci 2011). Furthermore, other co-integration techniques require larger sample sizes for validity, which is not the case for the ARDL procedure. The benefit from this co-integration technique is the fact that it provides a statistically more significant approach to determine the co-integration relation in small samples. The multicollinearity issue continues to exist even though the author has tested for collinearity and has excluded some of the variables that are highly correlated with the rest of the variables in the model.

From a contextual perspective a number of issues are relevant here. One is the influence of institutional development in Macedonia. As argued by the literature, the weak institutions in transition economies are a relevant factor that influences the further development of these economies and their growth Bocchi 2008; Giannetti and Ongena 2009; Hoskisson, Wright, Filatotchev and Peng 2013). There are a large number of studies that have focused on investigating the relationship between institutional development and growth in transition economies, but these studies use cross-country analysis (Beck and Leaven 2006; Bevan et al. 2004). These studies either use the institutional development index based on data from 18 different institutions and follow the theoretical construction of the index by Kaufman, Kray and Mastruzzi in 2004 (Beck and Leaven 2006) or use an institutional development index constructed by the European Bank for Reconstruction and Development, to which they have access (Bevan et al. 2004). Therefore, the institutional development factor was not taken into consideration because of the unavailability of the data.

Another aspect that is significant when analysing the growth of transition economies is their initial conditions (Berg and Pattillo 1999; Fischer and Sahay 2000; Havrylyshyn 2001). Again, due to the specificity of the context analysed in this paper, including initial conditions was impossible. This is again related to the unavailability of data. Moreover, before Macedonia's independence and the formation of the official SSORM, the country was part of the Yugoslav Federation, during which macroeconomic data was available at the Federal level rather than for each individual Republic. Thus, comparing the period before the country's independence and after this is not possible due to the limitations of the data. Through the comparison of 
the pre- and post-independence conditions, it would have been possible to determine the initial conditions with which the country was faced with during its independence and to include variables in the model that would reflect these initial conditions.

The quantitative analysis in this paper assisted in understanding the effects of specific macroeconomic determinants on GDP growth and the exploratory powers of the specific quantitative model. To the best of the author's knowledge this study is one of the first studies to specifically consider the role that economic reform plays in a transition economy, and the potentially different effects that it may have on the policy implications in such an economy. Aside from its limitations, this paper contributes to the wider debate of growth and reform by shedding light on specific policies that have a significant effect in the Macedonian transition economy.

\section{CONCLUDING SUMMARY}

By using the Pesaran, et al. (2001) auto regressive lag model (ARDL), the author provided an explanation of the extent to which traditional mainstream economic variables influence economic growth in Macedonia. The author took a pre-existing ARDL model used in another transition economy in order to investigate to what extent the widely used economic determinants explain economic growth in Macedonia. By shedding light on the explanatory power of mainstream economic variables to explain economic growth, the author provides an understanding on the factors that constrain growth in the Macedonian context.

The ARDL model used in this analysis assisted in determining the long-run significant relationship between the economic determinants and GDP. The analysis demonstrates the way statistically significant variables affect GDP, as well as which variables are not statistically significantly correlated with GDP. This suggests ways how policies can be improved based on the findings from the analysis above. However, it must be considered that the model as any other has its own limitations, which derive from the data used and the context for which it is implemented.

It should be underlined that the variables that have proven to not have a significant impact on GDP through the above analysis should not be dismissed, or that the model is wrong and does not have sufficient explanatory power. The author argues that the combination of the macroeconomic determinants used in the model above provide insight into how the Macedonian GDP can be explained through the limited data available. It is significant to highlight that Macedonia, being a small open economy that has become independent only 25 years ago, does not provide researchers with a great amount of data points and diversity of variables. More specifically, the data points used in this study cover a period of 21 years (1993 - 2014). Thus, the data the author has used for this analysis has proven to be limiting with regard to the richness of the findings. The data collected through official resources and the National Bank of Macedonia is also limited in terms of the diversity of the available data. Some of the variables were not included in the model because they simply are not available for the Macedonian economy.

The main focus of this study was on exploring how the process of economic reforms and transition of the Macedonian economy affected economic growth through the increase of its GDP. This paper highlighted the trade reforms implemented in the Macedonian economy and tested the effect of macroeconomic determinants on Macedonian GDP by using an Autoregressive distributed lag (ARDL) model. Having provided an initial analysis by considering the variables used in other mainstream economic models and data available for the Macedonian economy, this chapter shed light on the effect of traditional economic policies on economic growth. Therefore, the above discussion indicates that the findings are quite revealing and there is a need to conduct such an analysis in view of each country's unique characteristics. Since the main aim of this study was to investigate the links between trade liberalisation reforms and growth, this study has served its purpose and is a good contribution to the literature, particularly with regard to Macedonia.

Based on these research outcomes the following policy implications can be drawn: the most important task of the government in Macedonia is to further introduce trade liberalisation reforms to improve and increase export earnings by following an export-led growth strategy. This strategy for export diversification must be adopted to attain the best possible outcomes.

\section{REFERENCES:}

Aziz, J. and Wescott, R. 1997. Policy complementarities and the Washington consensus, IMF Working Paper: 97/118

Backé, P. and Gardó, S. 2012. Spillovers of the greek crisis to southeastern europe: manageable or a cause for concern?. Focus on European Economic Integration Q, 1.

Barro, R.J. and Sala - I - Martin, X. 1995. Economic Growth. McGraw - Hill, USA. 
Bartlett, W. 2009. Economic development in the European super-periphery: Evidence from the Western Balkans. Economic annals 54(181): 21-44.

Bartlett, W. and Prica, I. 2012. The variable impact of the global economic crisis in South East Europe, LSE- Research on South Eastern Europe

Beck, T. and Laeven, L. 2006. Institution building and growth in transition economies. Journal of Economic Growth. 11(2): 157-186.

Berg, A. and Pattillo, C. A. 1999. Are currency crises predictable? A test. IMF Staff Papers. 46 (2): 107-38.

Bevan, A. A. and Estrin, S. 2000. The determinants of FDI in transition economies. Discussion Paper No.2638. Center for Economic Policy Research, London.

Bevan, A., Estrin, S. and Meyer, K. 2004. Foreign investment location and institutional development in transition economies. International business review. 13(1): 43-64.

Bocchi, A.M. 2008. Rising Growth, Declining investment: The puzzle of the Philippines. The world bank, working paper.

Botrić, V. and Škuflić, L. 2006. Main determinants of foreign direct investment in the southeast European countries. Transition Studies Review. 13(2): 359-377.

Brown, R.L., Durbin, J. and Evans, J.M. 1975. Techniques for testing the constancy of regression relationships over time. Journal of the Royal Statistical Society. Series B (Methodological), 149-192.

Campos, N.F. and Kinoshita, Y. 2008. Foreign direct investment and structural reforms: evidence from Eastern Europe and Latin America. International Monetary Fund Institute, Washington DC.

DTIDZ (2014). Direkcija za tehnolosko industriski razvojni zoni, http://www.fez.gov.mk/povolnosti.html, (accessed on November 3, 2015).

Daud, S. N. M., Ahmad, H. A., and Azman - Saini, W. N. W. 2013. Does external debt contribute to Malaysia economic growth? Ekonomska Istrazivanja. 26(2): 51.

De Melo, M., Denizer, C., Gelb, A. and Tenev, S. 2001. Circumstance and choice: The role of initial conditions and policies in transition economies. The World Bank Economic Review. 15(1): 1-31.

Edwards, S. 1998. Openness, productivity and growth: what do we really know?. The economic journal, 108(447): 383-398.

Efendic and Pugh. 2015. Institutional effects on economic performance in post-socialist transition - a dynamic panel modelling. Acta Oeconomica, Vol. 65 (4), pp. 503-523

Expansion 2014. Republic of Macedonia: National debt. http://countryeconomy.com/national-debt/macedonia, (accessed on September 20, 2015).

Farrar, D.E. and Glauber, R.R. 1967. Multicollinearity in regression analysis: the problem revisited. The Review of Economic and Statistics, 92-107.
Fischer, S. and Sahay, R. 2000. The transition economies after ten years (No. w7664). National bureau of economic research.

Giannetti, M. and Ongena, S. 2009. Financial integration and firm performance: Evidence from foreign bank entry in emerging markets. Review of Finance, 13(2): 181-223.

Gore, C. 2000. The rise and fall of the Washington Consensus as a paradigm for developing countries. World development, 28(5): 789-804.

Greenaway, D., Morgan, W. and Wright, P. 2002. Trade liberalisation and growth in developing countries. Journal of development economics. 67(1): 229-244.

Harrison, A. and Hanson, G. 1999. Who gains from trade reform? Some remaining puzzles. Journal of development Economics. 59(1): 125-154.

Havrylyshyn, O. 2001. Recovery and growth in transition: a decade of evidence. IMF Economic Review, 48(1): 53-87.

Horvat, V. 2004. Brain drain. Threat to successful transition in South East Europe. Southeast european politics. 5(1): 76-93.

Hoskisson, R.E., Wright, M., Filatotchev, I. and Peng, M.W., 2013. Emerging multinationals from Mid-Range economies: The influence of institutions and factor markets. Journal of Management Studies, 50(7), pp.1295-1321.

Inder, B. 1993. Estimating long-run relationship in economics: a comparison of different approaches. Journal of Econometrics. 57: 53-68.

Johansen, S. and Juselius, K. 1990. Maximum Likelihood Estimation and Inference in Cointegration - With Application to the Demand for Money. Oxford Bulletin of Economics and Statistics. 52: 169- 210.

Kose, M. A., Prasad, E. S. and Terrones, M. E. 2003. Financial integration and macroeconomic volatility. IMF Staff papers. 119-142.

Krstevska, A. and Petrovska, M., 2012. The economic impacts of the foreign direct investments: panel estimation by sectors on the case of Macedonian economy. Journal of Central Banking Theory and Practice. 2: 55-73.

Leybourne S.J., Kim T. and Newbold P. 2005. Examination of some more powerful modifications of the Dickey-Fuller test. Time Series Anal. 26:355-69.

Liu, T.C. 1960. Underidentification, structural estimation, and forecasting. Econometrica: Journal of the Econometric Society, 855-865.

Mah, J. S. 2000. An empirical examination of the disaggregated import demand of Korea-The case of information technology product. Journal of Asian Economics. 11(2): 237-244

Manolova, T.S., Eunni, R.V. and Gyoshev, B.S. 2008. Institutional environments for entrepreneurship: Evidence from emerging economies in Eastern Europe. Entrepreneurship Theory and Practice. 32(1): 203-218. 
McKinnon, R. I. 1974. Money and capital in economic development. Washington: Brookings Institution Press.

Ozturk, I. and Acaravci, A. 2011. Electricity consumption and real GDP causality nexus: Evidence from ARDL bounds testing approach for 11 MENA countries. Applied Energy. 88(8): 2885-2892.

Pesaran, M. H. and Pesaran, B. 1997. Working with Microfit 4.0: Interactive

Econometric Analysis. Oxford University Press: Oxford.

Pesaran, M. H., Shin, Y. and Smith, R.J. 2001. Bounds testing approaches to the analysis of long-run relationships. Journal of Applied Econometrics. 16(3): 289-326.

Prasad, E.S., Rogoff, K., Wei, S. and Kose, M.A. 2003. Effects of financial globalization on developing countries: some empirical evidence. IMF Occasional Paper no. 220.

Rees, L. and Tyers, R. 2004. Trade reform in the short run: China's WTO accession. Journal of Asian Economics. 15(1): 1-31.

Rodriguez, F. and Rodrik, D. 2001. Trade policy and economic growth: a skeptic's guide to the cross-national evidence. NBER Macroeconomics Annual 2000, 15: 261-338. MIT Press.
Sachs, J.D. 1996. Economic transition and the exchange rate regime. The American Economic Review. 86(2): 147-152.

Shahbaz, M. 2012. Does trade openness affect long run growth? Cointegration, causality and forecast error variance decomposition tests for Pakistan. Economic Modelling. 29(6): 2325-2339.

Solow, R 1956. A contribution to the theory of economic growth. Quarterly Journal of Economics. 70(1): 65-94.

Stancheva - Gigov, I. 2014. The Impact of Foreign Trade on Economic Growth in Republic of Macedonia. Contemporary trends and prospects of economic recovery. 278.

Stiglitz, J. 2002. Globalization and its discontents. New York: W. W. Norton

Swan, T. 1956. Economic growth and capital accumulation. The Economic Record. 32: 334-361.

Tang, T. C. and Nair, M. 2002. A co-integration analysis of Malaysian import demand function: Reassessment from the bound test. Applied Economics Letters. 9 (5): 293-296.

Villanueva, D. P. 2003. External debt, capital accumulation and growth. SMU-SESS Discussion Paper Series in Economics and Statistics. 